\title{
Influence Of Commitment, Culture And Organizational Structure To Organizational Citizenship Behavior (Ocb) In Awal Bros Hospital
}

\author{
Muhammad Saddad Tanrewali ${ }^{1}$, Sukri Palutturi ${ }^{2}$, Reza Aril Ahri ${ }^{3}$ \\ 1. Universitas Patria Artha \\ 2,3. Universitas Muslim Indonesia \\ E-mail: m.saddad@patria-artha.ac.id
}

\begin{abstract}
Abstrak
Organizational Citizenship Behavior (OCB) yang dimiliki karyawan tidak boleh dipaksakan, harus tumbuh dengan kesadaran sendiri, hal ini dapat muncul apabila sesama karyawan memiliki ikatan kuat, rasa toleransi yang baik, pemimpin yang bijak dalam organisasi dan rendahnya konflik dalam organisasi. Penelitian ini bertujuan Menganilisis Pengaruh Komitmen, Budaya dan Struktur organisasi terhadap Organizational Citizenship Behavior (OCB) di RS Awal Bros Makassar. Jenis penelitian ini adalah studi analitik menggunakan analisis multivariat yang dilakukan dengan uji regresi logistik ganda dengan metode backward stepwise (conditional) Penelitian ini dilakukan pada karyawan (perawat) yang ada di RS Awal Bros Makassar. Sumber data diperoleh rmemalui Pengisisan kuesioner. Hasil Penelitian menunjukkan bahwa Ada pengaruh antara komitmen,budaya dan struktur organisasi dengan Organizational Citizenship Behavior (OCB) di RS Awal Bros Makassar serta Komitmen organisasi yang berpengaruh secara signifikan terhadap OCB. Berdasarkan hasil penelitian dan pembahasan diambil kesimpulan bahwa karyawan khususnya perawat yang ada di RS Awal Bros Makassar menunjukkan bahwa keterlibatannya dengan tugas-tugas pokok, Rasa memiliki, loyalitas yang tinggi, bertanggung jawab penuh terhadap pekerjaan, rasa cinta terhadap RS tanpa ada paksaan sudah dimiliki setiap karyawan. Mutu pelayanan yang diberikan, menciptakan suasana iklim kerja yang nyaman, bekerja sesuai kebijakan/aturan yang ada di RS, dan percaya pada rekan kerja dimana setiap pekerjaan yang overload sering diselesaikan secara bersama-sama sehingga pekerjaan terselesaikan tepat waktu serta mampu bertanggung jawab dengan tugas tambahan yang diberikan.
\end{abstract}

\section{Kata Kunci : Budaya, Komitmen, Pengaruh OCB, Struktur Organisasi}

\begin{abstract}
Organizational Citizenship Behavior (OCB) that employees should not be forced, should grow by its own consciousness, it can occur if fellow employees have a strong bond, tolerance is good, wise leader in the organization and lack of conflict within the organization. This research aims to analyze Influence of Commitments, culture and organizational structure to Organizational Citizenship Behavior (OCB) in Awal Bros Makassar. Kind of this research is an analytic study using multivariate analyzes were performed by multiple logistic regression with backward stepwise method (conditional) This research was conducted on employees (nurses) in Awal Bros Hospital Makassar. Sources of data is obtained through filling the questionnaires.

Research of results showed that There is influence between commitments, Culture and organizational structure with Organizational Citizenship Behavior (OCB) in Awal Bros Makassar and organizational commitment significantly influence $O C B$. Based on the results of research and discussion is concluded that employees, especially nurses in Awal Bros Hospital Makassar shows that involvement with basic tasks, sense of belonging, loyalty is high, fully responsible for the work, the love of the hospital without coercion is already owned by each employee. Quality of services delivered, creating an atmosphere of comfortable working climate, work according to the policy / rules that exist at the hospital, and trust in co-workers where each work overload often solved together so that the work gets done on time and be able to charge with additional tasks given.
\end{abstract}

Keywords: Culture, Commitment, Influence of OCB, Organizational Structure 


\section{Pendahuluan}

Rumah sakit umum sebagai salah satu fasiltas pelayanan kesehatan memegang peranan yang cukup penting dalam pembangunan kesehatan. Rumah sakit umum adalah rumah sakit yang memberikan pelayanan kesehatan semua jenis penyakit dari yang bersifat dasar sampai spesialistik. Tugas pokok rumah sakit umum adalah melaksanakan upaya kesehatan secara berdaya guna dan berhasil guna dengan mengutamakan upaya penyembuhan (kuratif) dan pemulihan (rehabilitatif) yang dilaksanakan secara serasi dan terpadu dengan upaya peningkatan (promotif) dan pencegahan (preventif) dengan melaksanakan upaya rujukan (Hartono, 2010).

Saat ini organisasi dituntut untuk bergerak dengan cepat, adaptif, tepat dan efisien. Sumber Daya Manusia merupakan salah satu faktor penggerak yang penting dari suatu organisasi. Kondisi-kondisi eksternal organisasi seperti globalisasi,perubahan iklim investasi,kondisi tenaga kerja,regulasi pemerintah, dan lain sebagainya merupakan faktor-faktor diluar kendali dari organisasi. Untuk mengatasi tekanan-tekanan faktor eksternal yang uncontrollable, maka suatu organisasi haruslah memperkuat kondisi internalnya, salah satunya adalah dengan pengelolahan Sumber Daya Manusia yang baik.

Namun setiap organisasi bukan cuma membutuhkan SDM yang berkualitas tetapi juga membutuhkan orang-orang yang mampu melakukan tugas diluar tugas yang seharusnya dilakukan bagi organisasi tanpa menuntut imbalan lebih untuk mendukung organisasi atau rumah sakit agar dapat bertahan dalam kompetisi bisnis dan mencapai perusahaan, perilaku karyawan seperti ini dinamakan Organizational Citizenship Behavior (OCB).

Organizational Citizenship Behavior (OCB) memiliki lingkup yang luas dibandingkan dengan komitmen karyawan secara pribadi karena arti dari Citizen itu sendiri adalah kewarganegaraan sehingga memiliki tanggung jawab dan rasa cinta terhadap pekerjaan secara sukarela dan tanpa diawasi. Karyawan yang memiliki OCB akan memiliki loyalitas yang tinggi terhadap organisasi tempatnya bekerja, dan dengan sendirinya akan merasa nyaman dan aman terhadap pekerjaannya. OCB berorientasi pada perilaku dan diharapkan perilaku khususnya yang berkaitan dengan sumber daya manusia.

Komitmen yang dimiliki oleh karyawan RS Awal Bros Makassar, mereka pada umumnya peduli dengan nasib organisasi dan berusaha menjadikan organisasi ke arah yang lebih baik, dengan berusaha loyal terhadap pekerjaan dibebankan kepada karyawan,Banyaknya jam tambahan diluar jam kerja (Shif Kerja Karyawan) yang tidak dibayarkan,

Budaya organisasional merupakan suatu sistem dari kepercayaan - kepercayaan dan nilai - nilai bersama dalam organisasi mengarahkan perilaku anggotanya. Oleh karena itu, disiplin, etos kerja dan Budaya organisasi karyawan saling mendukung dan ada keterkaitan, diprediksikan akan mudah terbentuk OCB (Robbins, 2015).

Untuk memiliki pegawai terampil yang memiliki kemampuan kerja, komitmen dan loyalitas yang tinggi terhadap instansi 
bukanlah suatu hal yang mudah karena banyak faktor yang mempengaruhinya, salah satunya adalah Budaya Organisasi (Organization Culture). Budaya Organisasi mengarahkan perilaku karyawan untuk meningkatkan kemampuan kerja, komitmen dan loyalitas, serta perilaku extra role seperti: membantu rekan kerja, sukarela melakukan kegiatan extra, menghindari konflik dengan rekan kerja, melindungi properti organisasi, menghargai peraturan yang berlaku, toleransi pada situasi yang kurang ideal/menyenangkan, memberi saran yang membangun, serta tidak membuangbuang waktu ditempat kerja.

Selain itu Struktur Organisasi juga mempengaruhi pribadi individu dan kelompok dalam Organisasi. Organisasi yang baik tentu memiliki Stuktur Organisasi yang baik. Para pemimpin memberikan ruang serta motivasi kepada karyawannya untuk meningkatkan produktivitasnya serta kualitas dalam memberikan pelayan akan tetapi karyawan merasa bahwa pekerjaan yang dilakukan kadang tidak sesuai dengan profesinya seperti perawat merangkap Petugas Administrasi, Petugas Gizi serta petugas Medical Record.

\section{Metode}

Jenis penelitian ini adalah studi analitik menggunakan analisis multivariat yang dilakukan dengan uji regresi logistik ganda dengan metode backward stepwise (conditional) Penelitian ini dilakukan pada karyawan (perawat) yang ada di RS Awal Bros Makassar. Sumber data diperoleh memalui Pengisisan kuesioner. Jumlah responden sebanyak 150 orang.

\section{Hasil}

Analisis Univariat

Tabel 1

Karakteristik responden berdasarkan Jenis Kelamin, Pendidikan dan Lama bertugas di RS Awal Bros Makassar

\begin{tabular}{lcc} 
Karakteristik & Frekuensi & \% \\
\hline Jenis Kelamin & & \\
Laki-Laki & 60 & 40 \\
Perempuan & 90 & 60 \\
\hline Pendidikan & & \\
D3 & 62 & 41,3 \\
S1 & 85 & 56,7 \\
S2 & 3 & 2 \\
\hline Lama Bertugas & & \\
0-2 tahun & 68 & 45,3 \\
3-5 tahun & 82 & 54,7 \\
\hline
\end{tabular}

Berdasarkan tabel diatas menunjukkan bahwa frekuensi Responden yang berjenis kelamin wanita sebanyak 90 orang $(60 \%)$ dan responden yang berjenis kelamin pria sebanyak 60 orang (40\%). Status lama bekerja secara berurutan yang paling lama bekerja adalah sebanyak 82 orang $(54,7 \%)$, dan yang baru adalah sebanyak 68 orang (45,3\%), Penelitian ini juga menunjukan bahwa responden yang mempunyai pendidkan terakhir D3 yaitu 63 orang (41,3 $\%$ ), yang berpendidikan S1 paling banyak 85 orang $(56,7 \%)$,dan berpendidikan terakhir S2 sebanyak 3 orang (2,0\%). 
Tabel 2

Tanggapan Responden Terhadap

Komitmen,Budaya dan Struktur organisasi di RS Awal Bros Makassar

\begin{tabular}{lcc}
\hline \multicolumn{1}{c}{ Variabel } & n & \% \\
\hline Komitmen organisasi & & \\
$\quad$ Baik & 95 & 63,3 \\
$\quad$ Kurang baik & 55 & 36,7 \\
Budaya organisasi & & \\
$\quad$ Baik & 105 & 70,0 \\
$\quad$ Kurang baik & 45 & 30,0 \\
Struktur organisasi & & \\
$\quad$ Baik & 104 & 69,3 \\
$\quad$ Kurang baik & 46 & 30,7 \\
OCB & & \\
Baik & 102 & 68,0 \\
Kurang baik & 48 & 32,0 \\
$\quad$ Total & $\mathbf{1 5 0}$ & $\mathbf{1 0 0}$ \\
\hline
\end{tabular}

Berdasarkan tabel diatas dapat dilihat bahwa untuk Komitmen organisasi dalam hal ini adalah Kewajiban dan tanggung jawab oleh karyawan harus dimiliki secara penuh, tempat lain tidak memberikan kompensasi sama atau lebih besar dari RS Awal Bros Makassar, dan sudah menjadi bagian dari hidup dan keluarga karyawan ada 63,3\% responden yang menganggap baik dan 36,7 $\%$ menganggap masih kurang baik.

Dari segi Budaya organisasi dalam hal ini perhatian dari Manajemen, percaya pada rekan kerja (selalu bekerja sama didalam tim), keteraturan yang bekerja sesuai standar pelayanan yang ada, sering terjadi perselisihan sesama perawat, serta Mutu pelayanan yang dilakukan oleh perawat ada $70 \%$ responden yang menyatakan baik dan $30 \%$ menyatakan kurang baik.

Struktur organisasi dapat dilihat bahwa 69,3 $\%$ responden menganggap baik terhadap tugas dan tanggung jawab yang dimiliki untuk menyelesaikan pekerjaan sesuai dengan kemampuan dan profesi serta mampu menyelesaikan tugas tambahan yang diberikan sedangkan sisanya 30,7\% masih menganggap kurang baik. Untuk OCB dapat dilihat bahwa $68,0 \%$ responden menganggap baik terhadap perilaku perawat untuk bekerja melebihi tugas / kewajiban dalam suatu pekerjaan (loyalitas yang tinggi terhadap suatu pekerjaan/profesi) dan $32 \%$ responden kurang baik.

\section{Analisis Multivariat}

Tabel 3

Pengaruh Komitmen, Budaya dan Struktur organisasi terhadap Organizational Citizenship Behavior (OCB) di RS Awal Bros Makassar

\begin{tabular}{|c|c|c|c|c|c|c|c|}
\hline \multirow{3}{*}{ Variabel } & \multicolumn{4}{|c|}{ OCB } & \multirow{2}{*}{\multicolumn{2}{|c|}{ Total }} & \multirow{3}{*}{$\underset{P}{\text { Nilai }}$} \\
\hline & \multicolumn{2}{|c|}{ Kurang baik } & \multicolumn{2}{|c|}{ Baik } & & & \\
\hline & $\mathbf{n}$ & $\%$ & $\mathbf{n}$ & $\%$ & $\mathbf{n}$ & $\%$ & \\
\hline \multicolumn{8}{|l|}{ Komitmen } \\
\hline Baik & 74 & 49,3 & 21 & 14,0 & 95 & 63,3 & \\
\hline Kurang baik & 28 & 18,7 & 27 & 18,0 & 55 & 36,7 & 0,001 \\
\hline Total & 102 & 68 & 48 & 32,0 & 150 & 100 & \\
\hline \multicolumn{8}{|l|}{ Budaya } \\
\hline Baik & 77 & 51,3 & 28 & 18,7 & 105 & $\mathbf{7 0 , 0}$ & \\
\hline Kurang baik & 25 & 16,7 & 20 & 13,3 & 45 & 30,0 & $\mathbf{0 , 0 2 7}$ \\
\hline Total & 102 & 68,0 & 48 & 32,0 & 150 & 100 & \\
\hline \multicolumn{8}{|l|}{ Struktur } \\
\hline Baik & 77 & 51,3 & 27 & 18,0 & 104 & 69,3 & \\
\hline Kurang baik & 25 & 16,7 & 21 & 14,0 & 46 & 30,7 & $\mathbf{0 , 0 1 5}$ \\
\hline Total & 103 & 68 & 48 & 32,0 & 150 & 100 & \\
\hline
\end{tabular}


Berdasarkan tabel diatas bahwa responden yang menganggap Komitmen organisasi baik terhadap OCB kurang baik yakni 74 responden (49,3\%) dan menganggap Komitmen organisasi baik terhadap OCB baik sebanyak 21 responden (14,0\%) sedangkan responden menganggap Komitmen organisasi kurang baik terhadap OCB kurang baik sebanyak 28 responden $(18,7 \%)$ dan menganggap Komitmen organisasi kurang baik terhadap OCB baik sebanyak 27 responden (18\%), Hasil analisis data uji statistik Chi Square Test tentang pengaruh Komitmen organisasi terhadap Organizational Citizenship Behavior (OCB) di RS Awal Bros Makassar, diperoleh nilai $\rho(0,001)<\alpha(0,05)$. Hal ini menunjukkan bahwa ada Pengaruh antara Komitmen organisasi terhadap Organizational Citizenship Behavior (OCB) di RS Awal Bros Makassar.

Responden yang menganggap Budaya organisasi baik terhadap OCB kurang baik yakni 77 responden $(51,3 \%)$ dan Budaya organisasi baik terhadap OCB baik adalah sebanyak 28 responden $(18,7 \%)$ sedangkan responden menganggap Budaya organisasi kurang baik terhadap OCB kurang baik sebanyak 25 responden $(16,7 \%)$ dan yang menganggap Budaya organisasi kurang baik terhadap OCB baik adalah 20 responden $(13,3 \%)$, Hasil analisis data uji statistik Chi Square Test tentang pengaruh Budaya organisasi terhadap Organizational Citizenship Behavior (OCB) di RS Awal Bros Makassar, diperoleh nilai $\rho(0,0027)<$ $\alpha(0,05)$. Hal ini menunjukkan bahwa ada pengaruh antara Budaya organisasi terhadap Organizational Citizenship Behavior (OCB) di RS Awal Bros Makassar.

Sedangkan Responden yang menganggap Struktur organisasi baik terhadap OCB kurang baik yakni 77 responden $(51,3 \%)$ dan Struktur organisasi baik terhadap OCB baik adalah sebanyak 27 responden (18,0\%) sedangkan responden menganggap Struktur organisasi kurang baik terhadap OCB kurang baik sebanyak 25 responden $(16,7 \%)$ dan yang menganggap Struktur organisasi kurang baik terhadap OCB baik adalah 21 responden $(14,0 \%)$, Hasil analisis data uji statistik Chi Square Test tentang pengaruh Struktur organisasi terhadap Organizational Citizenship Behavior (OCB) di RS Awal Bros Makassar, diperoleh nilai $\rho(0,0015)<$ $\alpha(0,05)$. Hal ini menunjukkan bahwa ada pengaruh antara Struktur organisasi terhadap Organizational Citizenship Behavior (OCB) di RS Awal Bros Makassar.

Tabel 4

Hasil Uji Regresi Pengaruh Komitmen, Budaya dan Struktur organisasi terhadap Organizational Citizenship Behavior (OCB) di RS Awal Bros

Variables in the Equation

\begin{tabular}{ccccccccc}
\hline Variabel & B & S.E & Wald & df & Sig. & $\operatorname{Exp~(B)~}$ & \multicolumn{2}{c}{$\mathbf{9 5 \% \text { .l.for EXP }}$ (B) } \\
\cline { 5 - 8 } & & & & & & & Lower & Upper \\
Komitmen & -1.126 &, 377 & 8.932 & 1 &, 003 &, 324 &, 155 &, 697 \\
Budaya & -698 &, 394 & 3,142 & 1 &, 076 &, 497 &, 230 & 1.077 \\
$\begin{array}{c}\text { Struktur } \\
\text { Costant }\end{array}$ & -688 &, 392 & 3,082 & 1 &, 079 &, 502 &, 233 & 1.083 \\
&, 836 &, 442 & 3,576 & 1 &, 059 & 2,308 & & \\
\hline
\end{tabular}


Berdasarkan analisis multivariat yang dilakukan dengan menggunakan uji regresi logistik ganda dengan metode backward stepwise (conditional). Sesuai dengan model tersebut yang di lakukan sampai beberapa tahap dapat dijelaskan bahwa variabel yang sangat signifikan terhadap Organizational Citizenship Behavior adalah variabel Komitmen dengan nilai koefisien sebesar 1.126 pada RS Awal Bros Makassar.

\section{Pembahasan}

Berdasarkan hasil dari penelitian dan pengolahan data yang telah disajikan adapun pembahasan untuk masing-masing variabel independen sebagai berikut :

\section{Komitmen Organisasi}

Komitmen organisasi adalah sebagai keadaan dimana seorang karyawan memihak pada satu organisasi dan tujuan-tujuannya serta berniat untuk memelihara keanggotaannya dalam organisasi tersebut (rasa loyalitas dan keterlibatannya dengan tugas-tugas yang ada disebuah organisasi). Rasa memiliki, bergairah,loyal dan bertanggung jawab terhadap pekerjaan serta rasa cinta terhadap Rumah Sakit tanpa ada paksaan ini dimiliki oleh setiap karyawan yang ada di RS Awal Bros Makassar

Berdasarkan dari hasil penelitian bahwa responden yang menganggap Komitmen organisasi baik terhadap OCB kurang baik yakni 74 responden $(49,3 \%)$ dan menganggap Komitmen organisasi baik terhadap OCB baik sebanyak 21 responden $(14,0 \%)$ sedangkan responden menganggap Komitmen organisasi kurang baik terhadap OCB kurang baik sebanyak 28 responden $(18,7 \%)$ dan menganggap Komitmen organisasi kurang baik terhadap OCB baik sebanyak 27 responden (18\%), Hasil analisis data uji statistik Chi Square Test tentang pengaruh Komitmen organisasi terhadap Organizational Citizenship Behavior (OCB) di RS Awal Bros Makassar, diperoleh nilai $\rho(0,001)<\alpha$ $(0,05)$. Hal ini menunjukkan bahwa ada Pengaruh antara Komitmen organisasi terhadap Organizational Citizenship Behavior (OCB) di RS Awal Bros Makassar.

Penelitian ini sejalan dengan Jurnal penelitan Danan (2006) mengemukakan bahwa ada hubungan antara Komitmen organisasi dengan OCB yang signifikan dengan $\mathrm{r}=0,288 ; \quad \mathrm{R} 2 \quad=0,83$ dan $\mathrm{p}$ Value $=0,001$, Penelitian lain yang sejalan dilakukan oleh (Utomo, 2008) bahwa Komitmen organisasi secara jelas berhubungan signifikan dengan OCB, Hasil penelitian ini juga sesuai dengan teori yang dikemukakan Luthans (2006) yang menyatakan bahwa Komitmen organisasi secara jelas berhubungan dengan OCB.

\section{Budaya Organisasi}

Budaya organisasi RS Awal Bros yang harmonis dan kondusif sehingga dapat menciptakan suasana iklim kerja yang nyaman,bekerja sesuai kebijakan/aturan yang ada di RS, percaya pada rekan kerja, disamping itu seringnya terjadi perselisihan antar karyawan akan tetapi MUTU pelayanan tetap dipertahankan ini dapat dibuktikan dengan Responden yang menganggap Budaya organisasi baik terhadap OCB kurang baik yakni 77 responden $(51,3 \%)$ dan Budaya organisasi baik terhadap OCB baik adalah sebanyak 28 responden $(18,7 \%)$ sedangkan responden menganggap Budaya organisasi kurang baik terhadap OCB kurang baik sebanyak 25 responden $(16,7 \%)$ dan yang menganggap Budaya organisasi kurang baik terhadap OCB baik adalah 20 
responden (13,3\%), Hasil analisis data uji statistik Chi Square Test tentang pengaruh Budaya organisasi terhadap Organizational Citizenship Behavior (OCB) di RS Awal Bros Makassar, diperoleh nilai $\rho(0,0027)<$ $\alpha(0,05)$. Hal ini menunjukkan bahwa ada pengaruh antara Budaya organisasi terhadap Organizational Citizenship Behavior (OCB) di RS Awal Bros Makassar.

Penelitian ini sejalan yang dilakukan Fitriani (2008) menyatakan adanya hubungan signifikan antara Budaya organisasi terhadap Organizational Citizenship Behavior (OCB). Puspita (2013) dalam penelitiannya menyatakan Budaya organisasi berpengaruh positif dan signifikan terhadap Organizational Citizenship Behavior (OCB) semakin baik Budaya organisasi maka semakin tinggi Organizational Citizenship Behavior (OCB) karyawan. Berbalik dengan penelitian yang telah dilakukan oleh Karim (2010) menyatakan bahwa tidak terdapat korelasi yang positif antara budaya organisasi dan OCB.

\section{Struktur Organisasi}

Struktur organisasi merupakan hubungan antar para karyawan dan aktivitas-aktivitas mereka satu sama lain serta terhadap keseluruhan bagian, tugas atau fungsi dari masing-masing anggota kelompok yang melaksanakannya. Karyawan di RS Awal Bros Makassar mampu mengerjakan dan menyelesaikan pekerjaan selain tugas tugas pokok profesi sebagai perawat seperti mampu menjadi petugas administrasi tanpa menyepelehkan tugas pokok sebagai perawat, selain itu selalu siap untuk menggantikan posisi kepala ruangan ketika didelegasikan tanpa ada paksaan, ini sejalan dengan penelitian bahwa Responden yang menganggap Struktur organisasi baik terhadap OCB kurang baik yakni 77 responden $(51,3 \%)$ dan Struktur organisasi baik terhadap OCB baik adalah sebanyak 27 responden $(18,0 \%)$ sedangkan responden menganggap Struktur organisasi kurang baik terhadap OCB kurang baik sebanyak 25 responden $(16,7 \%)$ dan yang menganggap Struktur organisasi kurang baik terhadap OCB baik adalah 21 responden $(14,0 \%)$, Hasil analisis data uji statistik Chi Square Test tentang pengaruh Struktur organisasi terhadap Organizational Citizenship Behavior (OCB) di RS Awal Bros Makassar, diperoleh nilai $\rho(0,0015)<$ $\alpha(0,05)$. Hal ini menunjukkan bahwa ada pengaruh antara Struktur organisasi terhadap Organizational Citizenship Behavior (OCB) di RS Awal Bros Makassar.

Struktur organisasi mempengaruhi perilaku baik individu dan kelompok dalam organisasi. Organisasi yang baik tentu memiliki Suktur organisasi yang baik. Struktur organisasi yang baik tentu akan menciptakan keteraturan yang kemudian membentuk perilaku organisasi yang baik.

Sejalan dengan penelitian yang dilakukan oleh Brahmasari (2008) menyatakan adanya hubungan antara Struktur organisasi terhadap Organizational Citizenship Behavior (OCB). Penelitian yang dilakukan oleh Sunarto (2009) tentang pengaruh struktur organisasi terhadap Organizational Citizenship Behavior (OCB) mencoba mencari korelasi antara struktur organisasi dan Organizational Citizenship Behavior (OCB) membuktikan bahwa struktur organisasi tidak berpengaruh terhadap Organizational Citizenship Behavior (OCB)

\section{Variabel yang berpengaruh signifikan terhadap Organizational Citizenship Behavior (OCB) di RS Awal Bros Makassar}

Berdasarkan analisis multivariat yang dilakukan dengan menggunakan uji regresi logistik ganda dengan metode backward stepwise (conditional). Sesuai dengan model 
tersebut yang di lakukan sampai beberapa tahap dapat dijelaskan bahwa variabel yang sangat signifikan terhadap Organizational Citizenship Behavior adalah variabel Komitmen dengan nilai koefisien sebesar 1.126 pada RS Awal Bros Makassar.

Ketiga variabel yang memiliki pengaruh yang memenuhi syarat untuk dilanjutkan dengan menganalisis secara simultan terhadap semua variabel terhadap Organizational Citizenship Behavior (OCB) dengan menggunakan uji regresi logistic dengan metode backward stepwise wald yaitu analisis yang membuang variabel yang paling tidak bermakna.

Kemudian dari hasil analisis data menunjukan bahwa variabel komitmen organisasi memiliki nilai $\rho=0,001<\alpha(0,05)$, variabel budaya organisasi memiliki nilai $\rho=0,027<\alpha(0,05)$, dan variabel struktur organisasi memilki nilai $p=0,015>\alpha(0,05)$ . dari hasil analisis dapat disimpulkan bahwa Komitmen organisasi, Budaya organisasi dan Struktur organisasi secara parsial berpengaruh terhadap variabel dependen.

Selanjutnya dilakukan analisis uji regresi logistik multivariat antara variabel Komitmen organisasi, Budaya organisasi dan Struktur organisasi dengan Organizational Citizenship Behavior (OCB) dimana hasil analisis menunjukan bahwa variabel Komitmen organisaslah berpengaruh signifikan terhadap Organizational Citizenship Behavior (OCB) di RS Awal Bros Makassar dengan $\rho=0,003$ dan wald $=8,932(<0,005)$.

Artinya ketika karyawan memiliki komitmen organisasional dalam menjalankan pekerjaannya, maka mereka memiliki OCB yang baik. Peningkatan komitmen organisasional akan mempengaruhi peningkatan OCB karyawan di RS Awal Bros Makassar Dengan kata lain, untuk meningkatkan OCB karyawan, maka pimpinan organisasi atau juga harus berupaya meningkatkan dan mempertahankan komitmen karyawan pada organisasi tersebut. Dengan Kkomitmen organisasional yang dimiliki karyawan maka OCB akan meningkat dan berpengaruh terhadap produktivitas.

\section{Kesimpulan}

1. Ada pengaruh antara Komitmen organisasi terhadap Organizational Citizenship Behavior (OCB) di RS Awal Bros Makassar dengan nilai $\rho(0,001)<$ $\alpha(0,05)$.

2. Ada pengaruh antara Budaya organisasi terhadap Organizational Citizenship Behavior (OCB) di RS Awal Bros Makassar dengan nilai $\rho(0,0027)<$ $\alpha(0,05)$

3. Ada pengaruh antara Struktur organisasi terhadap Organizational Citizenship Behavior (OCB) di RS Awal Bros Makassar dengan nilai $\rho(0,0015)<$ $\alpha(0,05)$.

4. Variabel komitmen organisasi adalah faktor yang paling signifikan berpengaruh dengan Organizational Citizenship Behavior (OCB) di RS Awal Bros Makassar nilai koefisien sebesar 1.126 dengan $\rho=0,003$ dan wald $=$ $8,932(<0,005)$.

\section{Referensi}

Allen, M. d. (1990). Commitmen in the workplace theory recearsh and aplication california: sage publication.

Brahmasari, A. (2008). Pengaruh motivasi kerja, kepemimpinan dan budaya organisasi terhadap kepuasan kerja karyawan serta dampaknya pada kinerja perusahaan. studi kasus pada PT pei Hai Internasional Indonesia wiratama, 2.

Donelly, G. d. (1996). Organisasi Prilaku Struktur Dan Proses. Jakarta: Binarupa Aksara. 
Danan. (2006). Hubungan kepuasan kerja dan komitmen organisasi dengan Organizational Citizenship Behavior (OCB) di Politeknik Kesehatan Banjarmasin Universitas Gadjah Mada, Yogyakarta

Fitriani. (2008). hubungan antara budaya organisasi dengan OCB pada dinas pendidikan kota cilegon.

Fred, L. (1998). Organisational Behavior. : sage publication.

Ghozali (2008). Model Persamaan Struktural Konsep Dan Aplikasi Dengan Program Amos 19,0. Jakarta, PT. Raja Grafind Persada.

Hartono. (2010). Manajement Pemasaran Rumah Sakit. Jakarta, Rineka Cipta.

Ivancevich. (2008). Perilaku dan Manajemen Organisasi. Jakarta. Erlangga

Karim, A. (2010). "Pengaruh Disiplin,Etos Kerja, Dan Budaya Organisasi Terhadap Organizational Citizenship Behavior Pegawai Administrator Pelabuhan Tanjung Priok." Home About Register Search Curret Archives13.

Kaller, K. P. d (2009). Manajemen Pemasaran. Jakarta: Erlangga

Luthans. (2006). Analisis keterkaitan antara kepuasan kerja, komitmen, budaya dengan kinerja individu Universitas Sam Ratulangi Manado, 2.

Mas"ud, F. (2004). Survei Diagnosional Konsep Dan Aplikasi Badan Penerbit: Universitas Diponegoro.

Muchlas, M. (2008). Prilaku Organisasi. Yogyakarta: Gajah Mada University Press.

Notoatmodjo, S. (2010). Metodologi Penelitian Kesehatan. Jakarta, Rineka Cipta.

Organ. (2006). Organizational Citizenship Behavior.Its Nature. Antecendents and Consequence.sage

Puspita, D. (2013). Pengaruh komitmen organisasi kepuasan kerja dan budaya organisasi terhadap Organizational citizenship behavior (OCB) studi PT plasa simpanglima semarang.

Parasuraman. (2009). Kualitas Pelayanan: Marketing Scinece Institut.

Robbins. (2003). Prilaku Organisasi. Jakarta: Salemba Medika.

Robbins. (2015). Prilaku Organisasi Jakarta: Salemba Medika.

Sukidjan, S. (2009). Komitmen Organisasi Sudah Menjadi Bagian Dari Kita. Jakarta: Alfabeta.

Suliyanto. (2006). Metode Penelitian.Yogyakarta, Andi Publisher

Sunarto. (2009). Pengaruh motivasi komitmen organisasi budaya organisasi terhadap kinerja pegawai. Unpad Bandung, 12.

Syamsir. (2016). Organisasi Dan Manajement. Bandung: Alfabeta.

Tjiptono. (2000). Manajemen Jasa. Yogyakarta.

Umar, H. (2014). Metode Penelitian Untuk Skripsi Dan Tesis Bisnis. Jakarta: PT Jara Grafindo Persada. 